\title{
TEORIAS DO CONHECIMENTO: ALGUMAS APROXIMAÇÕES COM A PESQUISA EM EDUCAÇÃO
}

\section{THEORIES OF KNOWLEDGE: SOME APPROACHES TO RESEARCH IN}

\section{EDUCATION}

Rosilene Moreira de SOUZA ${ }^{1}$

\begin{abstract}
Resumo: o trabalho aborda uma breve síntese dos fundamentos teóricos do positivismo, do materialismo histórico dialético, do idealismo e das abordagens teóricas modernas: as teorias crítica e pós-críticas, buscando entender as transformações na produção do conhecimento e as consequências dessa evolução na educação. A teoria crítica remete as perspectivas teóricas e analíticas que se centram no questionamento do papel que a escola, o currículo e a pedagogia representam na produção e reprodução do conhecimento e a teoria pós-crítica referem-se as pesquisas inerentes à questões de raça e etnicidade, classe, gênero, identidade e diferença, currículo, cultura e formação de professores e relações de poder na educação. Para que as pesquisas possam evoluir, no campo da educação é necessário consolidar o paradigma qualitativo que tem condições de captar o cotidiano das escolas, a essência do fenômeno educacional e o contexto na qual ela está inserida. A pesquisa e os estudos educacionais no Brasil precisam ser fortalecidos e melhorados rapidamente, para que isso ocorra é necessário o incentivo às pesquisas educacionais, pulverizadas no meio científico, e a quebra das barreiras institucionais entre educadores e não educadores e buscar novos conhecimentos e tecnologias, como condição para a melhoria da qualidade da educação.
\end{abstract}

Palavras-chave: Conhecimento. Teorias Científicas. Pesquisa em Educação.

Abstract: the work addresses a brief synthesis of the theoretical foundations of positivism, dialectical historical materialism, idealism and modern theoretical approaches: critical and postcritical theories, trying to understand the transformations in the production of knowledge and the consequences of this evolution in education. Critical theory refers to the theoretical and analytical perspectives that focus on the questioning of the role that school, curriculum, and pedagogy play in knowledge production and reproduction, and post-critical theory refers to the research inherent in issues of race and ethnicity, class, gender, identity and difference, curriculum, culture and teacher training and power relations in education. For research to evolve, in the field of education it is necessary to consolidate the qualitative paradigm that is able to capture the daily life of schools, the essence of the educational phenomenon and the context in which it is inserted. Educational research and studies in Brazil need to be strengthened and improved rapidly. For this to happen, it is necessary to encourage educational research, pulverized in the scientific environment, and to break institutional barriers between

\footnotetext{
${ }^{1}$ Doutoranda em Educação do Programa de Pós-graduação em Educação da Universidade Católica Dom Bosco (UCDB). Professora do curso de graduação em Pedagogia. E-mail: mrosilene9@ gmail.com.
} 


\section{HORIZONTES - REVISTA DE EDUCAÇÃO}

e-ISSN: 2318-1540

educators and non-educators and to seek new knowledge and technologies, as a condition for improving the quality of education.

Keywords: Knowledge. Scientific Theories. Research in Education.

\section{Introdução: o conhecimento científico e a evolução da ciência}

Os conhecimentos empíricos e teóricos do homem transmitidos através da cultura e da educação foram responsáveis pelo processo de socialização e evolução do ser humano. Gradualmente, o processo de produção de conhecimento evoluiu em decorrência da ordenação das ideias e do pensamento humano. As ideias, como uma consequência da vida humana, sofrem as mesmas determinações históricas e são a expressão das relações e atividades reais do homem, estabelecidas no processo de produção de sua existência (ANDERY et. al 1988, p. 12). As ideias como representações do ser humano são modificáveis, constantemente reelaboradas e seu desenvolvimento depende de fatores decorrentes de sua experiência de vida. Para os mesmos autores, a transformação das ideias em conhecimento científico é determinada pelas necessidades materiais do ser humano, trazendo contribuições para a evolução da ciência (Ibid., p.13).

A ciência pressupõe a solução de problemas, como acentuou Popper (POPPER, 1974 apud MATALLO JUNIOR, 2002, p. 24) nós temos uma tendência inata para a ordem e regularidade e quando esta expectativa não é satisfeita somos induzidos a procurar explicações para resolver a nossa problemática. Da necessidade de encontrar soluções para os problemas, surgem as teorias como forma de explicitar e contribuir para superar o problema e incentivar o crescimento e a evolução do conhecimento. Alves-Mazotti e Gewandsznajder (2002, p. 09) afirmam que a ciência progride, formulando teorias cada vez mais amplas e profundas capazes de explicar a variedade de fenômenos.

As teorias são isentas de opiniões e valores pessoais e são compostas por conceitos teóricos que são a parte essencial das teorias e das suposições dos pesquisadores, as teorias científicas são conjecturas que se apresentam como estruturas, que fornecem explicações, tanto para as regularidades como para as irregularidades da natureza (MATALLO JR, 2002, p. 27).

E não existe uma teoria, preposição ou fato que possa seriamente ser designada como verdadeira. As informações que hoje são consideradas verdadeiras podem ser contrapostas no 


\section{HORIZONTES - REVISTA DE EDUCAÇÃO}

e-ISSN: 2318-1540

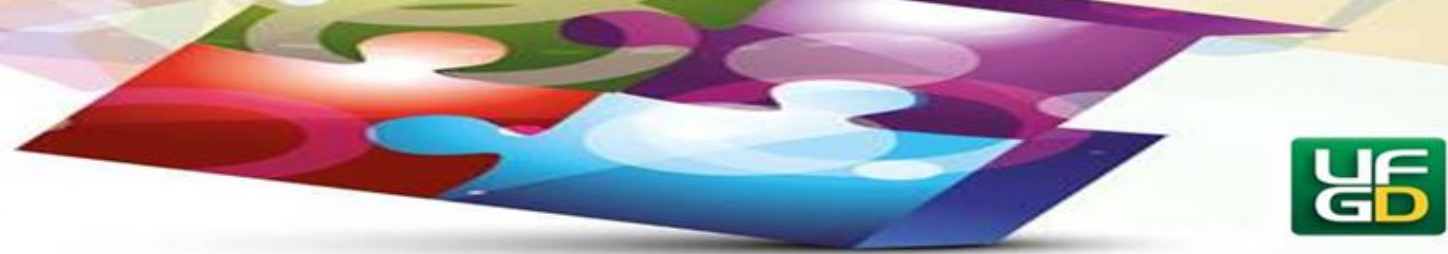

futuro e deixarem de ser verdade. Para Alves-Mazotti e Gewandsznajder (2002, p. 09) afirmar que a ciência é objetiva não significa dizer que suas teorias são verdadeiras.

A objetividade da ciência não repousa na imparcialidade de cada indivíduo, mas na disposição de formular e publicar hipóteses para serem submetidas a críticas por parte de outros cientistas; na disposição de formulá-las de forma que possam ser testadas experimentalmente; na exigência de que a experiência seja controlada e de que outros cientistas podem repetir os testes, se isto for necessário.

A partir das teorias criadas para explicitar as conjecturas e para elucidar os problemas surgiu a necessidade de criação de um método para colocar à prova essas conjecturas, teorias e hipóteses. Segundo Chalmers (1997, p. 15) Francis Bacon (1561-1626) foi um dos primeiros a se preocupar com o método na ciência moderna, propondo que a meta da ciência é o melhoramento da vida do homem na terra e, para ele, essa meta seria alcançada através da coleta de fatos com observação organizada e derivando teorias a partir daí. A ciência como forma de produzir invenções aplicadas a natureza, reveladas nas ideias de Francis Bacon foram importantes na defesa do uso do método científico (empirismo). Defendia que a obtenção dos fatos verdadeiros se dava através da observação e experimentação (regulada pelo raciocínio lógico).

A fé que outrora oferecia segurança, sentido para a vida e conhecimento não mais satisfazia essa necessidade, surge então a necessidade de criar uma nova fonte de certezas e verdades. Em busca de um novo começo, Descartes (2009, p. 33) propõe a superação das metas individuais e a busca de uma razão universal, desconsiderando as tradições, os costumes, crenças e partindo da premissa de "duvidar de tudo" para construir certezas ou a "dúvida metódica”. Para Descartes (2009, p. 33), a criação do método seria a solução para a pluralidade de razões. Algumas características do método proposto por Descartes: excluir tudo o que gera dúvida, o que não foi claro e evidente; dividir o problema em problemas menores e começar a resolvê-los pelos mais simples; ordenar os pensamentos dos mais simples aos mais complexos, articulando a relação entre eles; revisar as conclusões de modo a ter certeza de que nada foi esquecido, que as conclusões sejam claras e distintas. Para Descartes " a verdade está acessível a todos" $(2009$, p. 33). 


\section{HORIZONTES - REVISTA DE EDUCAÇÃO}

Descartes (2009) em seus escritos reforça alguns dogmas: o engano ocorre também na academia; os costumes são diferentes; crítica da tradição; a importância da lógica; a tradição filosófica sob suspeita; o costume não é a fonte da verdade; a ciência como tarefa individual.

Os passos do método podem ser assim descritos:

[...] o primeiro era nunca aceitar coisa alguma como verdadeira, sem que a conhecesse evidentemente como tal, ou seja, evitar cuidadosamente a precipitação e a prevenção e não incluir em meus juízos nada além daquilo que se apresentasse tão clara e distintamente a meu espírito, que eu não tivesse nenhuma ocasião de pô-lo em dúvida; o segundo passo, dividir cada uma das dificuldades que examinasse em tantas parcelas quantas fosse possível e necessário para melhor resolvê-las; o terceiro, conduzir por ordem meus pensamentos, começando pelos objetos mais simples e mais fáceis de conhecer para subir pouco a pouco, como por degraus, até o conhecimento dos mais compostos; e supondo certa ordem entre aqueles que não se procedem naturalmente uns aos outros; e o último passo fazerem enumerações tão completas e revisões tão gerais que eu tivesse a certeza de omitir (DESCARTES, 2009, p. 35).

Descartes (2009) não teve muita dificuldade em concluir por onde era necessário começar, pois já sabia que era pelas mais simples e mais fáceis de conhecer e, considerando que entre todos aqueles que até agora procuraram a verdade nas ciências, só os matemáticos puderam encontrar algumas demonstrações, isto é algumas razões certas e evidentes.

[...] não duvidou de que deveria começar pelas mesmas coisas que eles examinavam, embora delas não esperasse nenhuma outra utilidade a não ser a de acostumarem o espírito a alimentar -se de verdades e a não se contentar com falsas razões (DESCARTES, 2009, p. 36).

Descartes (2009) propôs uma instrumentalização da natureza, a explicação matemática e racional dos fenômenos e das coisas e a sua mecanização: tudo passa a ser entendido em razão das partes que o compõem: para se compreender o todo, basta compreender as partes.

$\mathrm{O}$ entendimento de que o conhecimento se constrói mediante a indução (pensamento indutivo) ou mediante a dedução (pensamento dedutivo) está na base das grandes tendências epistemológicas que fundamentam a pesquisa.

Essas tendências podem ser agrupadas em três grandes abordagens: empírico-analítica, fenomenológico-hermenêutica e histórico dialética e as abordagens críticas e pós críticas, que mais frequentemente têm orientado a pesquisa em ciências sociais e humanas e especialmente na educação, foco dos nossos estudos. 


\section{Abordagem Empírico-analítica}

Importante filósofo do Empirismo Britânico, do século XVIII, David Hume (17111776) é conhecido por sua posição filosófica baseada no ceticismo, empirismo e naturalismo, posição esta que desenvolveu como um sistema filosófico abrangente. Tendo início na obra Tratado da Natureza Humana, de 1739, na qual Hume procurou examinar a base psicológica da natureza humana, esta posição o levou a concluir ser o comportamento humano governado pela paixão e não pela razão, argumentando contra o racionalismo, ao qual o empirismo se opunha com veemência. O desenvolvimento desta posição também o levou a afirmar uma ética sentimentalista, a qual seria baseada nos sentimentos ou emoções humanas, em oposição a uma ética baseada em princípios morais abstratos.

Para o mesmo Hume ( 2004), os filósofos abstratos enganam-se facilmente e um engano gera outros enganos, ao passo que os filósofos simples logo reconhecem o engano e retomam o caminho certo. Segundo Hume (2004) o caminho da felicidade está nas avenidas da ciência e da instrução é possível colher prazer naquilo que parece árduo e laborioso. No texto, "da origem das ideias" (HUME, 2004, p. 33) o autor afirma que há diferença entre experiência concreta e a recordação, Hume afirma que faz experiência para ter a ideia. E, por conseguinte, dividir todas as percepções do espírito em duas classes ou espécies, que se distinguem por seus diferentes graus de força e de vivacidade. As menos fortes e menos vivas são geralmente denominadas pensamentos ou ideias (HUME, 2004 p. 34). Prova disso é que os pensamentos dependem da experiência.

Com relação “a ideia de conexão necessária" Hume afirma que para atingir um conhecimento total da ideia de poder ou de conexão necessária, devemos examinar sua impressão e, a fim de desvendar a impressão com maior segurança, busca-se em todas as fontes das quais ela possivelmente deve derivar.

Quando olhamos em torno de nós na direção dos objetos externos e consideramos a ação das causas, não somos jamais capazes, a partir de um único caso, de descobrir algum poder ou conexão necessária, alguma qualidade que ligasse o efeito à causa e tomasse um a consequência infalível do outro. Apenas constatamos que um, realmente, segue o outro. O impulso de uma bola de bilhar é acompanhado pelo movimento de segunda. Eis tudo que se manifesta aos sentidos externos. O espírito não sente nenhuma sensação ou impressão interna em virtude desta sucessão de objetos; por conseguinte, 


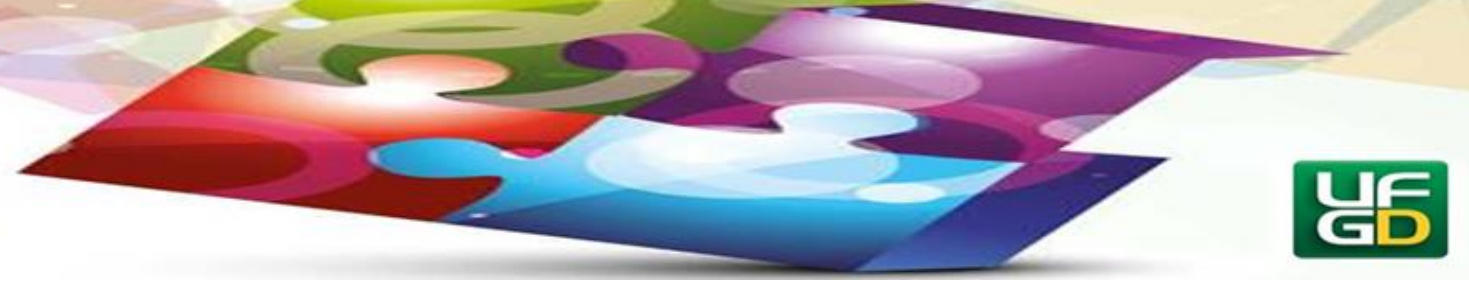

não há, num só caso isolado e particular de causa e efeito, nada que possa sugerir a idéia de poder ou de conexão necessária (HUME, 2004 p. 45).

Um importante aspecto à discussão acerca do método científico foi adicionado por Hume (2004) ao afirmar que, para elaborar-se as premissas necessárias a um raciocínio indutivo, é preciso utilizar o próprio raciocínio indutivo, o que resultaria em uma argumentação circular. Assim sendo, não estamos racionalmente justificados a confiar em raciocínios indutivos e, portanto, não podemos afirmar que o futuro será como o passado, o fato de que temos de supor a constância para poder afirmar que o evento acontecerá novamente mostra que não há razão para pensar que será assim, apenas estamos acostumados a pensar que os eventos, irão se repetir devido a termos experiênciado a sua repetição no passado. Este tópico é conhecido como "problema da indução" (HUME, 2004, p. 115) uma questão que permeia as pesquisas e os pesquisadores de modo geral.

\section{Positivismo}

O positivismo ou empirismo lógico que nasceu no meio científico em resposta ao "obscurantismo filosófico" (BUNGE, 1980, p. 104), foi fundado por Augusto Comte e tinha como preocupações fundamentais, uma filosofia da história, base da filosofia positiva e a "lei dos três estados”. Esses princípios se caracterizavam pela evolução do pensamento humano: teológico, metafísico e positivo, a classificação das ciências por área e a criação da sociologia.

[...] a lei dos três estados, segundo a qual todas as sociedades evoluem, está carregada de sentido ideológico profundo. O que se pretende, é mostrar que as sociedades seguem uma marcha inevitável que corresponde a sua natureza. A ordem inerente a cada estado é inalterável em seus aspectos fundamentais. Mas, avança, progride, nos seus aspectos morais e intelectuais, até alcançar a plenitude no Estado Positivo (AMES, 1991, p. 71).

O positivismo evoluiu em três fases: a primeira fase é denominada positivismo clássico, em seguida o empírico-criticismo e na terceira etapa o neopositivismo. Este último se desdobra no positivismo lógico, o empirismo lógico, o atomismo lógico, a filosofia analítica, o behaviorismo e o neobehaviorismo (TRIVIÑOS,1992, p. 33).

O positivismo consagra a ciência como a única forma válida de conhecimento (CUPANI, 1989, p. 13) proclama como função essencial da ciência a capacidade de prever. O 


\section{HORIZONTES - REVISTA DE EDUCAÇÃO}

e-ISSN: 2318-1540

verdadeiro espírito positivo consiste em ver para prever (TRIVIÑOS, 1992, p. 35) e tem como características principais a consideração do fenômeno isoladamente, sem levar em conta o contexto inserido; a capacidade de enxergar os fatos que possam ser observados, e o interesse em desvendar as relações causais (a identificação das causas), espinha dorsal do positivismo.

[...] foi com o advento do Positivismo, principalmente o comteano, que a noção tradicional de objetividade se consolidou, porque ela responde, em grande medida, ao esforço dos positivistas em retratar teoricamente o que imaginavam ser a conduta bem-sucedida dos cientistas naturais. Nesta abordagem, a objetividade do conhecimento científico foi atribuída, fundamentalmente, ao respeito aos fatos, entendidos como ocorrências devidamente certificadas pela observação sistemática, à diferença, não só de fantasias e ilusões, senão também da mera especulação, embora coerente. Esta maneira de entender a objetividade acentua-se no neopositivismo do começo do nosso século, no qual à fidelidade ao empiricamente dado à consciência acrescentou-se a exigência da formulação do conhecimento científico em linguagens estritamente lógicas (CUPANI, 1989, p. 20).

\section{Abordagem fenomenológico-hermenêutica.}

A fenomenologia, derivada do humanismo, uma tendência do idealismo filosófico e do denominado idealismo subjetivo. Pode ser definida como o estudo ou a ciência do fenômeno. Como tudo o que aparece é fenômeno, o domínio da fenomenologia é praticamente ilimitado. Essa corrente está preocupada com a redução do fenômeno à sua essência, mediante a redução eidética, método da fenomenologia pelo qual o fenômeno se apresentava puro, livre dos elementos pessoais e culturais, chega-se a um nível de apreensão do fenômeno que se denomina essências. Esse reducionismo leva a “fenomenologia a apresentar-se como um 'método' e como um 'modo' de ver o dado" (TRIVIÑOS, 1992, p. 42) ou uma maneira de fazer ciência. Para a fenomenologia, a história também é circunstancial, uma vez que não se preocupa em estudar a historicidade dos fenômenos:

A busca da essência, isto é, o que o fenômeno verdadeiramente é, depois de sofrer um isolamento total, uma redução, eliminando o eu que vivencia o mundo com seus valores, cultura, etc., carece de toda a referência que não seja a de sua pureza como fenômeno, de modo que o comportamento histórico, que tão pouco interessava ao positivismo, não é tarefa que preocupe o pesquisador que se movimenta orientado pelos princípios da fenomenologia (TRIVIÑOS, 1992, p. 47). 


\section{HORIZONTES - REVISTA DE EDUCAÇÃO}

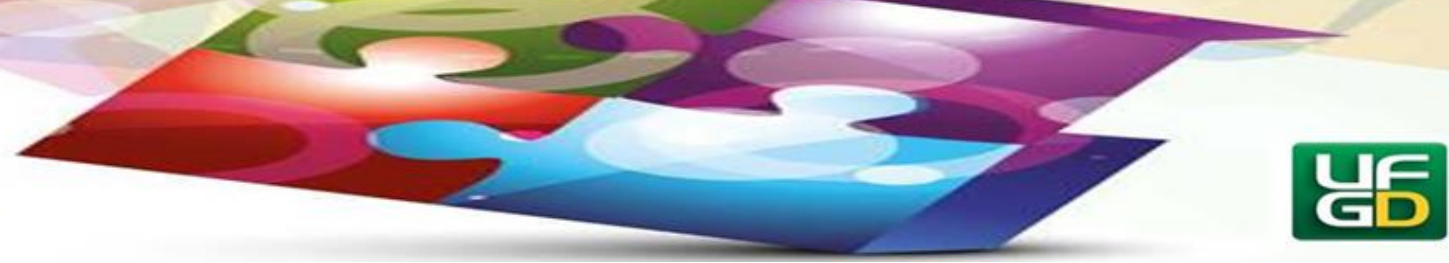

A categoria fundamental da fenomenologia é a intencionalidade. Para Husserl (1988), a intencionalidade é algo puramente descritivo, uma particularidade íntima de algumas vivências. A fenomenologia está preocupada com a interpretação dos fatos, que é intencional, o que importa na pesquisa são as percepções do sujeito sobre o fenômeno. A fenomenologia deslocou o objeto de conhecimento e passou a enfatizar o sujeito causando consequências extraordinárias e a perspectiva filosófica é essencial à constituição de uma fenomenologia que se quer rigorosa.

A fenomenologia baseada na interpretação dos fenômenos, na intencionalidade da consciência e na experiência do sujeito (TRIVIÑOS, 1992, p. 47). A fenomenologia requer o exercício da implicação, ou seja, estar em aberto a problemática da pesquisa e não atuar como sujeito lógico. O pesquisador não é isento ao realizar a sua pesquisa e o modelo observacional sobre uma determinada realidade é de alguma forma uma maneira de modificar a realidade.

Toda a construção do conhecimento tem uma estrutura intencional, modelo ou forma intencional. $\mathrm{Na}$ fenomenologia o princípio está em cada pesquisador, em cada caso imerso em seu mundo de vida, a pré concepção do seu entorno diluídas nas próprias experiências.

\section{Abordagem histórico-dialética}

A abordagem histórico - dialética, derivada da doutrina marxista; é vista como uma tentativa de síntese do empírico-analítico e do fenomenológico dialético. O materialismo histórico-dialético criado por Marx e Engels é a base filosófica do Marxismo e realiza a tentativa de buscar explicações coerentes, lógicas e racionais para os fenômenos da natureza, da sociedade e do pensamento (TRIVIÑOS, 1992, p. 51).

Para Trivinõs (1992), a concepção materialista apresenta três características importantes. A primeira, é a materialidade do mundo, postulando que todos os fenômenos, objetos e processos são materiais e correspondem a aspectos da matéria em movimento. A segunda, ressalta que a matéria é anterior à consciência, o que significa reconhecer que a consciência é um reflexo da matéria. E, a terceira, afirma que o mundo é conhecível, e parte da possibilidade do homem de conhecer a realidade e se desenvolver gradualmente (TRIVIÑOS, 1992, p. 52). O materialismo dialético vai tentar apreender o fenômeno na sua gênese, no seu desenvolvimento. 


\section{HORIZONTES - REVISTA DE EDUCAÇÃO}

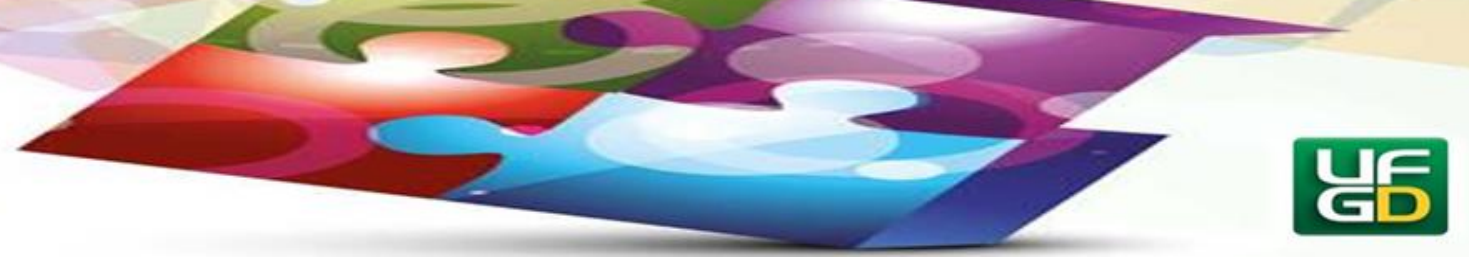

As leis e as categorias são a essência do materialismo dialético. As categorias são os conceitos de: matéria: consciência e prática social. Algumas leis do materialismo dialético são denominadas de: lei da passagem da quantidade a qualidade; lei da interpenetração dos contrários; lei da negação da negação.

A teoria crítica originou-se do pensamento de um grupo de intelectuais marxistas não ortodoxos, alemães, que, a partir dos anos 1920, desenvolveram pesquisas e intervenções teóricas sobre problemas filosóficos, sociais, culturais, estéticos gerados pelo capitalismo tardio e influenciaram sobremaneira o pensamento ocidental particularmente dos anos 40 aos anos 70 do século passado (PUCCI, 1995, p. 3). Esse movimento mundial foi no sentido de romper com a teoria tradicional funcionalista e o ingresso na teoria crítica e rompimento com a teoria crítica de viés mais marxista. O marxismo foi a base da teoria crítica do século XX. Ele recebeu outras influências e as principais categorias analíticas foram: "classe, conflito, alienação, dominação, exploração, racismo, sexismo, dependência, sistema mundial, teologia da libertação" (SANTOS, 1999, p. 200).

Dentre os seus teóricos precursores da teoria crítica destacam-se Max Horkheimer (1895-1973), Herbert Marcuse (1898-1979), Theodor Adorno (1903-1969), Jürgen Habermas (1929). O termo "teoria crítica" se consagrou a partir do artigo de Max Horkheimer, em 1937 "Teoria tradicional e teoria crítica" em que o autor prefere utilizar essa expressão para fugir da terminologia "materialismo histórico" utilizada pelo marxismo ortodoxo, hegemônico na época, e por querer mostrar que a teoria de Marx era atual, mas devia se importar em suas reflexões com outros aspectos críticos presentes na abordagem da realidade: o filosófico, o cultural, o político, o psicológico e não se deixar conduzir predominantemente pelo economicismo determinista.

Nas reflexões de Boaventura de Souza Santos (1999) sobre o por que é tão difícil produzir teoria crítica hoje, o autor afirma que muitos conceitos perderam sua força crítica ou foram ressignificados de tal modo que não mais expressam um potencial crítico; e pela dificuldade de encontrar posições alternativas em relação ao que existe.

Um dos problemas da teoria crítica moderna, na visão de Santos (1999) foi não perceber que a razão que crítica não pode ser a mesma que construiu o que está sendo criticado, ou seja, faltou fazer a crítica epistemológica. Com isso, mesmo que a intenção era produzir um conhecimento-emancipação, produziu um conhecimento-regulação. O ponto de partida da 


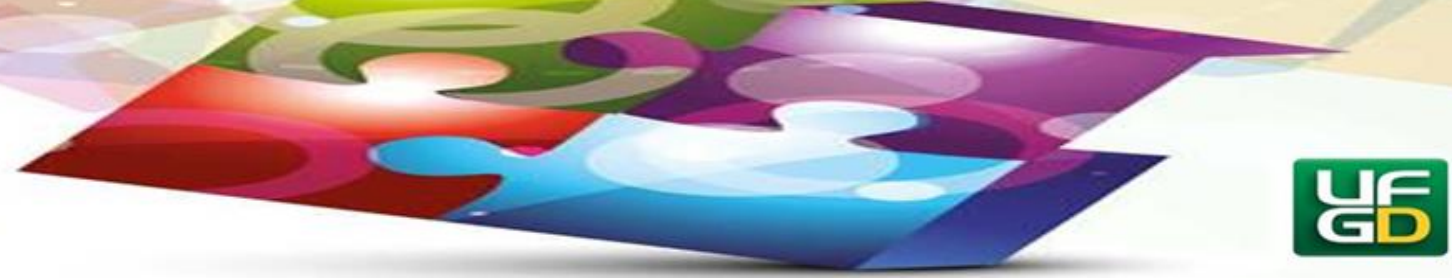

teoria crítica pós-moderna é a crítica do conhecimento, ver o outro não como objeto, mas como sujeito do conhecimento.

Dentro das ciências humanas há várias formas de produzir conhecimento. A educação contemporânea atual é pós-moderno. O termo pós crítico, significa "supercrítico" e, pressupõe a transformação dos princípios da modernidade.

Para Silva (2000, p. 17) as teorias pós-críticas discutem identidade, alteridade, diferença, subjetividade, significação e discurso, saber-poder, representação, cultura, gênero, raça, etnia, sexualidade e multiculturalismo.

Para Paraiso (2004) a pesquisa educacional na perspectiva pós- crítica pressupõe diagnóstico as potencialidades do campo; discute as temáticas da época com outras perspectivas. Temáticas como as reformas educacionais, construtivismo, as metodologias participativas, as discussões de gênero, etc.

Linhas e contornos dos estudos pós- críticos leva em conta a das relações de poder na educação;

[...] poder como produtivo, capilar, inerente as relações sociais; a do sujeito (identidade, subjetividade e modos de subjetivação); problematiza-se a arrogância, o silêncio, o currículo sexista, urbano, etnocêntrico, heteronormativo. Problematização da identidade e das diferenças, como nos tornamos o que somos. Por que queremos determinados sujeitos. Problematiza-se a formação de professores [...] enfim mostra-se como diferentes sujeitos são produzidos e fabricados, defendem que o sujeito não existe fora da escola, da linguagem, do discurso, e das relações de poder (PARAISO, 2004, p. 289).

A teoria pós- crítica em educação se preocupa ainda com a descrição e análise da artificialidade da produção de saberes da educação, questionando todas as verdades incluindo as consideradas boas no campo da educação, como as abordagens democráticas, libertadoras, transformadoras e cidadãs. Ao mesmo tempo que mostram o caráter artificial e inventado de todas as verdades questionando o porque consideramos determinados conhecimentos legítimos e outros não.

\section{As Abordagens e suas relações com a pesquisa educacional}




\section{HORIZONTES - REVISTA DE EDUCACÃO}

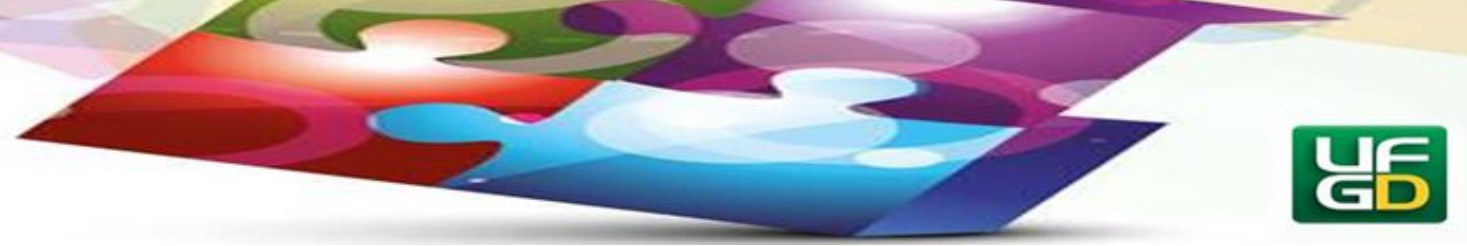

No campo educacional, segundo Alves-Mazotti e Gewandsznajder (2002, p. 119) a pesquisa realizada numa abordagem empírico-analítica possui caráter quantitativo como fator de destaque. Na fenomenologia as pesquisas são desenvolvidas apenas mediante a metodologia qualitativa. Na abordagem histórico-dialética predominam pesquisas que envolvem abordagem qualitativa e quantitativa dos fenômenos. As teorias críticas e pós críticas utilizam a abordagem qualitativa na realização das suas pesquisas. Para Alves-Mazotti e Gewandsznajder (2002, p. 119) o enfraquecimento do paradigma identificado com as técnicas quantitativas fez surgir o paradigma qualitativo uma alternativa ao modelo de investigação utilizado pelas ciências naturais.

[...] para a teoria crítica, a subjetividade [...] não é algo que tenha que ser expurgada da pesquisa, e sim precisa ser admitido e compreendido como parte da construção de significados inerentes às relações sociais que se estabelecem no campo pesquisado (ALVES-MAZZOTTI, 2001, p. 140).

É importante lembrar com Alves-Mazzotti, que

[...] na atividade científica, a crítica não é uma forma de destruir o conhecimento e sim uma forma de construí-lo. A teoria crítica parte do entendimento de que [...] nenhum processo social pode ser compreendido de forma isolada, como uma instância neutra acima dos conflitos ideológicos da sociedade (2001, p. 139-145).

Para a utilização dessas metodologias no campo da educação e, sobretudo, da pesquisa educacional algumas considerações são importantes. Alves-Mazzotti (2001, p. 14) ressalta, a importância do pesquisador conhecer o contexto social que a escola está inserida, já que faz parte de uma sociedade e para que o pesquisador não perca de vista o seu papel na formação do indivíduo e a sua totalidade. A escola é a mediadora entre a condição concreta da vida da clientela que nela ingressa e a destinação social dessa clientela.

Na pesquisa educacional no Brasil existe uma espécie de divisão do trabalho entre os especialistas em educação, que tratam dos aspectos pedagógicos e curriculares do ensino, e os pesquisadores que analisam os aspectos científicos para a solução dos problemas educacionais. Uma dicotomia entre os que pensam e os que fazem. Na prática, isso significa que os professores não se beneficiam dos conhecimentos de natureza mais científicos, e que as questões pedagógicas acabam sendo desvinculadas da prática. 


\section{HORIZONTES - REVISTA DE EDUCAÇÃO}

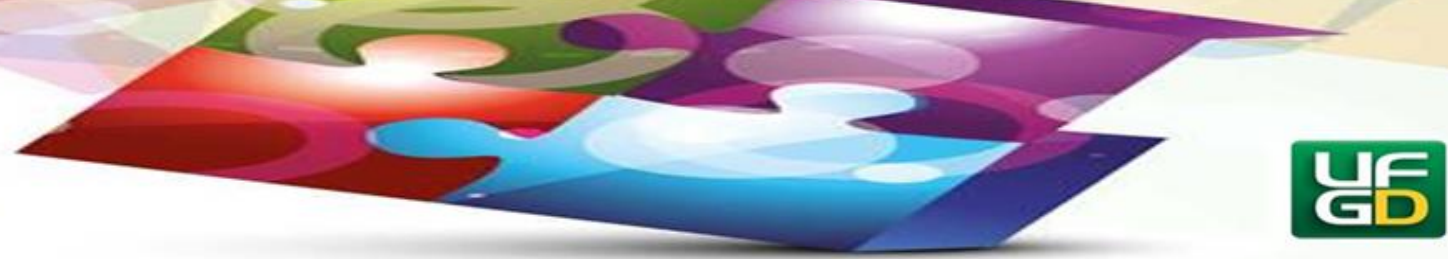

É necessário que a pesquisa educacional deixe os redutos científicos e de fato passe a integrar a realidade da escola. A interagir com os professores de forma que os mesmos possam ser, não somente objetos de pesquisa, mas também, sujeitos do processo de novas descobertas que podem transformar sua prática e o fazer pedagógico das escolas.

A posição de André e Lüdke sobre a pesquisa educacional é que:

[...] ela se situa dentro das atividades normais do profissional da educação, seja ele, professor, administrador, orientador,..etc. Não queremos com isso subestimar o trabalho da pesquisa como função que se exerce rotineiramente, para preencher expectativas legais. O que queremos é aproximá-la da vida diária do educador, em qualquer âmbito que ele atue, tornando-a um instrumento de enriquecimento do seu trabalho (1986, p. 2).

Para Alves-Mazotti e Gewandsznajder (2002, p. 144) alguns dos estudos científicos educacionais no Brasil não possuem um aprofundamento teórico e metodológico em relação ao fenômeno estudado, os temas escolhidos são irrelevantes, há uma seleção das teorias metodológicas por modismo, aplicação imediata dos resultados e com pouca interferência na prática. As pesquisas são pouco divulgadas, os estudos costumam ser muito específico, limitando a pesquisa e a aplicação ao local de trabalho do pesquisador o que resulta em pesquisas fragmentadas e irrelevantes, que pouco contribuem para o conhecimento e para a prática mais ampla.

\section{Considerações finais}

As teorias do conhecimento científico são muito importantes para que a pesquisa seja vista como um trabalho coletivo e tenha objetividade, sobretudo na pesquisa em educação, no sentido de poder ser examinada e criticada por outros pesquisadores, para que haja um crescimento científico. Ao não situar seu objeto de pesquisa em uma discussão mais ampla, o pesquisador reduz a questão estudada ao recorte de sua própria pesquisa. É fundamental que haja uma preocupação dos pesquisadores em produzir no âmbito das ciências educacionais pesquisas com rigor científico. Para Alves-Mazotti (2001) as pesquisas podem ser quantitativas ou qualitativas desde que favoreçam a distinção entre o conhecimento confiável de outras práticas sociais, para contribuir na resolução dos problemas vigentes em nosso país. 


\section{HORIZONTES - REVISTA DE EDUCAÇÃO}

e-ISSN: 2318-1540

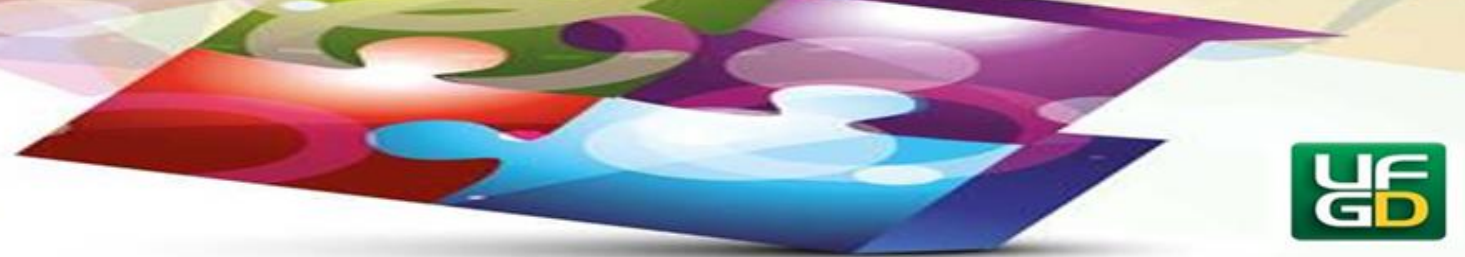

André e Lüdke (1986) afirmam que para que as pesquisas possam evoluir, sobretudo, no campo da educação é necessário consolidar o paradigma qualitativo que tem condições de captar o cotidiano das escolas, a essencial do fenômeno educacional e o contexto na qual ela está inserida.

A abordagem quantitativa e qualitativa dos problemas da educação é defendida por Gatti (2002, p. 29):

É preciso considerar que os conceitos de qualidade e quantidade não são totalmente dissociados, na medida em que de um lado a quantidade é uma interpretação, uma tradução, um significado que é atribuído à grandeza com que um fenômeno se manifesta, e de outro ela precisa ser interpretada qualitativamente, pois, sem relação a algum referencial teórico não tem significação em si.

A pesquisa e os estudos educacionais no Brasil precisam ser fortalecidos e melhorados rapidamente, para que isso ocorra é necessário a destinação de maiores recursos de incentivo as pesquisas educacionais, até hoje pulverizadas no meio científico e quebrar as barreiras institucionais entre educadores e não educadores e buscar novos conhecimentos, como condição para a melhoria da qualidade de nossas escolas e, por conseguinte, da educação brasileira.

\section{Referências}

ALVES-MAZZOTTI, A. J. O método nas ciências sociais. In. ALVES-MAZZOTTI, Alda Judith; GEWANDSZNAJDER, Fernando. O método nas ciências naturais e sociais: pesquisa quantitativa e qualitativa. São Paulo: Pioneira, 2001. p. 109-188

ALVES-MAZZOTTI, A. J.; GEWANDSZNAJDER, F. O método nas ciências naturais e sociais: pesquisa quantitativa e qualitativa. São Paulo: Pioneira Thomson Learning, 2002. p. 109-187.

AMES, J.L. A filosofia da dominação em Augusto Comte. Revista de Filosofia. v. 4, n. 4, jul. 1991.

ANDERY, M.A. et al. Para compreender a ciência. Rio de Janeiro: Espaço e Tempo, 1988.

ANDRÉ.M; LÜDKE, M. Pesquisa em educação: abordagens qualitativas. São Paulo: EPU. 1986.

BUNGE, M. Ciência e desenvolvimento. Belo Horizonte: Itatiaia, 1980. 


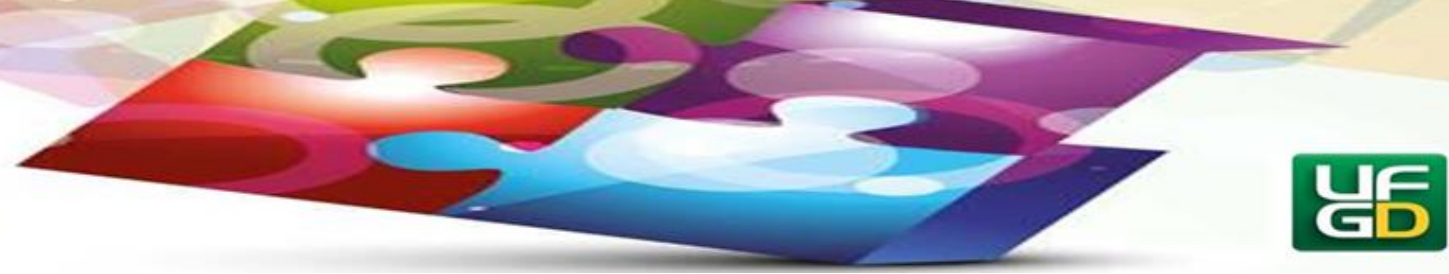

CHALMERS, A. F. O que é ciência afinal? São Paulo: Brasiliense.1997.

CUPANI, A. A objetividade científica como problema filosófico. Cad. Cat. Ens. Fís., Florianópolis, 6 (especial), p. 18-29, jun. 1989.

DESCARTES, R. Discurso do método. São Paulo: Martins Fontes, 2009.

GATTI, B. A. A construção da pesquisa em educação no Brasil. Brasília: Plano Editora, 2002.

GIDDENS, A. As consequências da modernidade. São Paulo: UNESP, 1991.

HUME, D. Uma investigação sobre o entendimento humano. São Paulo: UNESP,2004.

HUSSERL, E. Investigações lógicas. Dordrecht: Kluwer Academic Publishers1988.

LAUX, E.R.T. O problema da indução de Hume a Popper: a confiabilidade da ciência na visão de Hume e Popper, tendo por base a questão da indução. Controvérsia, v. 8, n. 1, p. 1221, jan./abr. 2012.

LYOTARD, J.F. A condição pós-moderna. Rio de Janeiro: José Olympio, 2009.

MATAllO JUNIOR, H. A problemática do conhecimento. Campinas: Papirus, 2002.

PARAISO, M.A. Pesquisas pós-críticas em educação no Brasil: esboço de um mapa.

Cad.Pesq., v. 34, n. 122, p. 283-303, ago. 2004.

PUCCI, Bruno (Org.). Teoria Crítica e Educação: A Formação Cultural na Escola de Frankfurt. Petrópolis: Vozes, 1995

SANTOS, B.S. Porque é difícil construir uma teoria crítica? Revista Crítica de Ciências Sociais, 54, p. 197-215, 1999.

SILVA, T.T. Documentos de identidade: uma introdução as teorias do currículo. Belo Horizonte: Autêntica, 2000.

TRIVIÑOS, A.N.S. Introdução à pesquisa em ciências sociais: a pesquisa qualitativa em educação. São Paulo: Atlas. 1992.

Enviado: 19/12/2018.

Aceito: 24/05/2019. 